\title{
ESTABELECENDO INTERAÇÕES DE AJUDA COM PACIENTE HIPERATIVO*
}

\author{
Maria da Glória Lima** \\ Antonia Regina Furgato Rodrigues
}

\begin{abstract}
RESUMO: O enfermeiro psiquiátrico tem expandido seu papel e vem definindo melhor suas funções utilizando-se a si próprio como instrumento terapêutico fundamentado na relação interpessoal terapêutica voltada para a pessoa que precisa de ajuda. Os objetivos deste estudo são: 1) apresentar as interações do enfermeiro com um paciente hiperativo em um hospital psiquiátrico com características custodial e terapêutica; 2) analisar o procedimento do enfermeiro à luz do referencial teórico das relações interpessoais. São apresentados trechos de 4 encontros. Da análise pudemos perceber o nivel de envolvimento e comprometimento em cada encontro; observar melhora na capacidade de observação e intervenção do enfermeiro; momentos de ansiedade do paciente e do enfermeiro; momentos de intervenções inadequadas e terapêuticas.
\end{abstract}

ABSTRACT: The psychiatric nurse has broadened his role and better defined his functions, using himself as a therapeutic instrument in developing a therapeutic interpersonal relationship with a person in need of help. The purpose of this study is: 1) to present the interactions between a nurse and a hyperactive patient of a psychiatric ward of a hospital with custodial and therapeutic character; 2) to analyze the nurse's interventions in light of the interpersonal relationship theory. Four encounters were analyzed, from which the authors were able to observe: the level of involvement and commitment present in each encounter; the increasing ability of the nurse to observe and intervene; moments of patient and nurse's anxiety and situations of inadequate and therapeutic interventions.

\section{INTRODUÇÃO}

Hoje o papel do enfermeiro psiquiátrico vem ampliando-se, na tentativa de acompanhar e participar do avanço e contribuições de algumas ciências, como sociologia, antropologia, comunicação, que ampliam conceitos, levando os profissionais a se questionarem e a procurarem dar uma assistência de forma mais humanizada.

O papel do enfermeiro psiquiátrico na saúde mental tem-se estendido, da área clínica da enfermagem psiquiátrica, para uma assistência mais ampla, assumindo o papel de terapeuta junto ao cliente, pa- ciente e/ou família, fundamentado na relação interpessoal positiva, que também pode ser denominada de relação pessoa a pessoa. Essa relação terapêutica, e/ou relação de ajuda, tem como princípio a atenção voltada para o cliente, existindo na literatura várias tentativas de definição e de entendimento dessa questão.

ROGERS $^{(8)}$ entende a relação de ajuda como uma relação na qual pelo menos uma das partes procura promover na outra o crescimento, o desenvolvimento, a maturidade, um melhor funcionamento e uma maior capacidade de enfrentar a vida promovendo o crescimento pessoal.

Para MUCCHIELLI ${ }^{(3)}$, a relação de ajuda é uma

* $\quad$ Trabalho realizado a partir do projeto elaborado na disciplina "Enfermagem nas diversas terapias psiquiátricas" da Pós-graduação em Enfermagem Psiquiátrica - nível mestrado - Escola de Enfermagem de Ribeirão Preto - USP.

** Professora Auxiliar do Departamento de Enfermagem da Universidade de Brasília. Mestranda da Escola de Enfermagem de Ribeirão Preto - USP.

*** Professora Assistente Doutor do Departamento de Enfermagem Psiquiátrica e Ciências Humanas da Escola de Enfermagem de Ribeirão Preto-USP. 
relação profissional na qual uma pessoa deve ser assistida para operar seu ajustamento pessoal a uma situação à qual ela não se adaptava normalmente. Isso supõe que o ajudador seja capaz de duas ações específicas:

$1^{\text {a) }}$ Compreender o problema nos termos em que se coloca para-tal indivíduo singular em sua existência singular.

$\left.2^{\mathrm{a}}\right)$ Ajudar o cliente a evoluir pessoalmente no sentido de sua melhor adaptação social.

BENJAMIN $^{(1)}$, diz que ajudar é um ato de capacitação. O entrevistador capacita o entrevistado a reconhecer, sentir, saber, decidir e escolher se deve mudar... A entrevista de ajuda é a ampla interação verbal entre entrevistador e entrevistado, na qual se dá o ato de capacitação.

TRAVELBEE ${ }^{(11)}$ coloca, que a relação de pessoa-a-pessoa, constitui uma meta a ser alcançada. É o resultado final de uma série de interações planificadas entre dois seres humanos: a enfermeira e o paciente. É também uma série de experiências para os participantes, durante as quais ambos desenvolvem uma capacidade crescente para estabelecer relações interpessoais.

Até o momento, nossa preocupação junto ao paciente era tornar cada encontro significativo, fazer uma interação a cada encontro. Hoje, estudando a "relação de ajuda", vemos que o terapeuta pode oferecer, ajudar muito mais ao paciente, se tiver por base um referencial teórico que sistematize e oriente suas ações.

PEPLAU $^{(4)}$ foi a primeira enfermeira a preconizar, para a profissão, uma teoria humanizadora da assistência centrada no relacionamento interpessoal. Ela mostrou que a pessoa do enfermeiro é um instrumento muito importante na relação enfermeiro-paciente, e as atitudes que este assumir, terão alto grau de influência no resultado da interação. A partir de seus estudos, o enfermeiro deixa de atuar sobre, para estar com o paciente. Afirma ainda que, a relação interpessoal é um processo que envolve conceitos, definições e proposições, enfim, um método que não deve ser empregado cegamente pela enfermagem.

Sua teoria não provocou mudanças imediatas na enfermagem. Surgiu num momento em que a enfermagem, procurando impor-se como profissão cientificamente reconhecida, preferiu acompanhar o movimento tecnicista da prática e positivista do conhecimento. Assim, vemos agora, 40 anos depois, uma tendência em resgatar o que já existe na literatura para se tentar humanizar a assistência de enfermagem.

TRAVELBEE ${ }^{(11)}$ fez um estudo profundo das relações de pessoa-a-pessoa, preocupada com o ensino desse método para o aluno de enfermagem psiquiátrica. Para ela, é essencial que o enfermeiro tenha conhecimentos e habilidades para estar seguro, a fim de executar e avaliar os resultados do seu trabalho junto á pessoa que precisa de ajuda. Analisa todos os passos da relação de pessoa-a-pessoa: observação, interpretação, tomada de decisão, ação e avaliação da ação.

Em nosso meio, MINZONI ${ }^{(2)}$ fez os primeiros estudos nessa linha e começou a passar os conhecimentos através do ensino e da assistência de enfermagem em saúde mental. STEFANELLI ${ }^{(9,10)}$ vem aprofundando-se nos estudos da comunicação enfermeiro-paciente a nível do ensino e da pesquisa. Traz para a enfermagem a análise de várias autores dessa linha e a aplicação dos conceitos de comunicação terapêutica à enfermagem psiquiátrica.

RODRIGUES ${ }^{(7)}$, num estudo da assistência de enfermagem em saúde mental junto a mulheres em crise, desenvolveu um relacionamento de ajuda onde preconiza três momentos distintos e formula um Modelo de Procedimento de Enfermagem de Saúde Mental (MPESM). A partir desse estudo, vem aprofundando os estudos da humanização da assistência através das interações terapêuticas enfermeiro-paciente ${ }^{(6,7)}$ Tem também ensinado enfermeiros a centrarem suas ações de enfermagem na pessoa que requer ajuda, como é o caso do presente estudo, desenvolvido à partir da disciplina "Relacionamento Interpessoal Enfermeiro-Paciente".

\section{OBJETIVOS}

1. Apresentar as interações do enfermeiro com um paciente psiquiátrico.

2. Analisar o procedimento do enfermeiro à luz do referencial teórico das relações interpessoais terapêuticas.

\section{RELAÇÃO DE AJUDA ENFERMEIRO- PACIENTE}

a) Identificação do Paciente

AFGP do sexo masculino, 24 anos, solteiro, espírita, com $2^{\circ}$ grau incompleto, desempregado.

A escolha do paciente deu-se por sugestão dos auxiliares da enfermagem após explicação dos moti- 
vos do estudo. Falaram de um paciente, A.F.6P, que andava muito agressivo, rasgando os colchões e falando desconexo.

No momento, não havia pacientes nas enfermarias, pois era dia de São Vicente de Paula e estava sendo celebrada uma Missa no pátio.

O paciente foi encontrado no corredor quando descia para ir ao pátio. Segundo o funcionário que o acompanhava, ele não conseguia ficar quieto na Missa. Perguntei seu nome, ele respondeu dizendo se chamar A.F.. Apresentei-me dizendo quem eu era e colocando-me á disposição para ajuda-lo, tentando estabelecer o contrato de ajuda e ele aceitou.

\section{b) Primeira entrevista}

A primeira entrevista foi realizada numa enfermaria da ala masculina. O paciente mostrava-se inquieto, ansioso, com expressão eufórica.

E* - Você gostaria de falar sobre algum tema específico hoje?

$\mathrm{P}^{* *}$ - Sim, gostaria de falar sobre o que você quiser, gostaria de falar de tudo: do amor, da vida, de sexo, do mundo, sobre o que você quiser.

E - Não gostaria de falar sobre o motivo que o troxe aqui?

P - Meu pai me internou, queria vender o carro para me ajudar a fazer o tratamento.

E - Mas porque seu pai te internou?

P - Você não é Adriana, minha prima?

E - Não, eu sou G., enfermeira.

P - Porque eu fumava maconha, mexia com LSD e cocaína, mas cocaína eu só gosto de cheirar, não gosto de pico. Mas eu estou muito bem.

E - Quando foi que começou a usar drogas?

P - Eu tinha 16 anos.

$\mathrm{E}-\mathrm{O}$ que pensa sobre isto?

P - Nada. Você é tia Diva.

E - Não, eu sou G., enfermeira. (A enfermeira mantém contato com a realidade).

P - Ah sim, me desculpe. (Começa a cantar o hino com o meu nome. Pergunto se ele quer continuar a entrevista, ele responde que sim).

E - Como você começou a usar drogas?

P - Por influência dos namorados das minhas irmãs. Elas também usam.

E - E como se sente usando drogas?

P - Bem, calmo, relaxado. Eu sempre quis fazer alguma coisa; eu sempre tive uma índole de querer ajudar os outros, dar alguma coisa, só que as pessoas não gostavam de mim.

E - Por que você diz isso?

P - Porque eu falava sempre a verdade e eles não gostavam.

E - E quem você acha que estava certo?

P - Acho que era eu, mas agora acho que não, já que eu estou aqui.

Durante todo este tempo o paciente mostrava-se inquieto, ansioso. Deitava-se e levantava-se da cama; as vezes andava, ficava murmurando, como se estivesse rezando e pedindo desculpas a todo momento.

Pediu para sair para acender um cigarro e beber água.

Retornou, pediu desculpas e perguntou quando é que sua mãe iria busca-lo de alta, pois já se sentia bem e queria alta.

Tentei conversar sobre o comportamento dele, do nível de ansiedade em que se encontrava. Ele concordava e dizia que era porque estava preso no hospital e que acabaria ficando doido porque não tinha nada para fazer: "Você me tira daqui? Me deixa sair..."

Expliquei que não poderia dar sua alta, mas que estava ali para ajudá-lo no que fosse possível.

Foi ao banheiro e voltou falando sobre sexo, que não entendia sobre sexo, mas que hoje ele compreende.

\section{E - Como assim?}

Paciente usou uma expressão grosseira e fazendo gesto representando o que estava falando. Tentou passar a mão na minha perna e novamente coloquei o objetivo da minha presença junto a ele. Desculpou-se e tornou a falar de sexo.

* E - enfermeira

** $\quad$ P - paciente 


\section{E - E como você vê sexo hoje?}

P - Bom, mas as pessoas são complicadas, explicando que hoje as pessoas só queriam fazer sexo e mais nada, não param para pensar.

Relata ter tido uma experiência aos 5 anos de idade com uma vizinha. Fala de outra experiência com a idade de 11 anos, tendo relação anal numa posição passiva, citando nomes de colegas e também o pai, com quem teria mantido esta relação. Percebe a confusão que estava fazendo, conta outras histórias semelhantes, falando ter vergonha dessas experiências.

Fala que aos 16 anos teve a primeira namorada, que foi bom, mas que foi ficando sério e leve que acabar e que namorar agora, é transar pois ninguém se importa mais com o outro; é cada um por si.

E - E você também sente assim?

P - Eu queria curtir, gostar, sentir as pessoas.

E - Você não está curtindo?

P - Não, está difícil (Pede para sair para beber água).

Falei que teríamos outros encontros e que continuaríamos na próxima entrevista. Perguntei se ele gostaria de continuar a conversar sobre como ele se sentia com as outras pessoas, dos seus relacionamentos. Paciente concorda. Definimos também datas dos próximos encontros.

\section{c) Segunda Entrevista}

Quando cheguei à unidade, o paciente estava com a mãe e outra pessoa que me apresenta como sendo sua noiva. Depois desmentiu dizendo que era sua irmã. Estava sorridente e afetivo com ambas. Falava para a mãe que eu era enfermeira e que estava tratando dele e pediu-me que contasse a ela o que nós tínhamos falado. Perguntei porque ele mesmo não falava. Paciente mudou de assunto dizendo que eu daria sua alta. Expliquei o meu papel ali e afastei-me para que pudessem se despedir.

Após o término da visita, perguntei se gostaria de falar sobre seus pais. Respondeu que gostava muito deles, que dava-se mito bem com a mãe, que eram muito amigos e que com o pai não se entendia bem, mas que o amava. Pediu para não falar sobre eles.

Paciente não conseguia ficar quieto numa posição: levantava, sentava, andava, dizendo que estava sentindo muito calor, tirando e vestindo a camisa; pediu para ficar sem roupa. Concordei que estava realmente fazendo muito calor e perguntei o que ele pensava sobre ficar sem roupa conversando comigo. Respondeu que os outros achariam que ele estava doido mesmo. Continuou inquieto: deitava, levantava, ficava andando em círculos, ora quieto, ora rezando, ora cantando.

P - Me tira daqui. Só você pode me ajudar, me dá alta.

E - Já conversei com você sobre isso ontem, você sabe que eu não posso lhe dar alta.

P - Mas minha mãe vai me tirar daqui agora.

Explico que sua mãe veio apenas visitá-lo e que não voltaria hoje para tirá-lo. Paciente irrita-se dizendo que eu estava mentindo, pediu para que eu saísse dizendo estar cansado e que não queria conversar mais comigo.

E - Você não quer falar comigo hoje ou não quer conversar mais nenhum dia?

P - Não quero conversar mais, nem hoje nem nunca mais. Agora estou cansado.

Falei que de qualquer forma, eu voltaria na sexta e se ele não quisesse mais conversar eu aceitaria a sua decisão.

Esta entrevista durou mais ou menos 10 minutos. Mais tarde eu estava no posto e o paciente tentou chamar minha atenção, pedindo água e objetos de uso pessoal, por várias vezes. Depois disse que gostaria de continuar a conversa. Coloquei que, no momento, não era possível mas que eu voltaria amanhã.

Nesse caso, ficou evidente que não fui terapêutica. Não levei o paciente a refletir e concluir acertadamente sobre sua alta, sobre minha função, sobre seu estado de saúde. Ele não tinha condições de enfrentar a realidade do enfermeiro sem as elaborações pessoais. Depois, quis resgatar a chance de continuar as interações mas novamente o enfermeiro estacou nos seus princípios e ele "teve" que aceitar.

P - Oi, vamos continuar conversando?

E - Você quer?

P - Quero conversar sobre o que você quiser.

E - Não é sobre o que eu quero, mas sim o que você gostaria de falar, estou aqui para ajudá-lo.

Silêncio. Por ansiedade do enfermeiro frente ao silêncio, ele introduz um tema que o paciente já tinha rejeitado noutra oportunidade. Tanto é que ele mudou de assunto imediatamente. 
E - Não quer falar sobre os seus pais, como se sente em relação a eles? (Paciente interrompe e fala de religião, cantando música religiosa, fazendo gesto de quem está rezando).

Começa a falar do pai, dizendo que não se dá com ele, mas que o ama. Fala que o pai é militar, e muito rígido e que queria que ele fosse militar também. Fala da mãe de maneira carinhosa e afetuosa.

Interrompe, pedindo sua alta, o qual pondero com ele. Reinicia dizendo que mudou depois que começou a usar drogas, que sua família não aceita e que seu pai pensa em mandá-lo embora.

\section{E - O que você pensa sobre isso?}

P - Mas eu não uso mais maconha, nunca mais vou fumar maconha e cheirar cocaína. Volta a falar dos pais.

A entrevista é dirigida no sentido de que o paciente perceba os sentimentos das pessoas de quem ele fala: dos pais, irmãs, amigos e do porquê das dificuldades que ele levanta nesses relacionamentos e de como ele utiliza a droga (coloca que é para "viajar", se sentir mais disposto e se colocando numa posição de não-dependente).

Vai ao banheiro e pede para falar de sexo, repetindo as histórias da primeira entrevista e falando de contatos homossexuais na adolescência, afirmando que atualmente não mantém relações homossexuais e que não sente prazer em tais relações e sente-se incomodado por lembrar essas coisas.

Pede as suas roupas pessoais dizendo que se sentia muito mal com o pijama do hospital, querendo rasgar a blusa. Respondi que eu o entendia e que não seria desta forma rasgando camisa, colchões que seriam resolvidos os seus problemas e que procurasse conversar com mais calma. Paciente aceita e pede para continuar a conversa no pátio por causa do calor.

No pátio, sentamos em um banco. O paciente apresentando a expressão triste e angustiada dizia que se sentia muito só, e que ninguém gostava dele. Disse que estava muito carente, pedindo para segurar a minha mão, no que concordei.

Havia outros pacientes no pátio. Ele começa a falar que vários não gostavam dele, que não o procuravam, que ficavam xingando-o, dizendo que era um sem-vergonha e que só bagunçava. $O$ paciente refere que os seus pais também falavam que ele não prestava.

Pedi para que ele se colocasse no lugar de cada uma dessas pessoas e como é que se sentiria se tivesse que falar, conviver com uma pessoa como ele agindo daquela forma. Paciente para, pensa e diz que da mesma forma, só que ele tentaria conversar, para entender o que se passava com ele.

Perguntei se ele procurava os outros para conversar, dialogar, respondeu que não, que sentia muita dificuldade. Falei que dificilmente as pessoas o aceitariam se ele continuasse agindo desta forma. Ficou pensativo por alguns instantes e pediu para ir ao banheiro. Antes que saísse, propus continuar na próxima entrevista a dificuldade que sentia com as pessoas e a problemática da droga. Paciente aceitou estes temas.

Esta entrevista teve a duração de mais ou menos 50 minutos. Paciente apresentava sinais de impregnação medicamentosa: sialorréia, atividade motora lentificada, ansioso. Foi orientado em relação à sua medicação. Na prescrição médica já havia sido reduzida a dosagem da medicação. O médico que o acompanhava estava viajando para participar de um congresso e ele estava sendo visto apenas quando apresentava intercorrências como agitação e impregnação.

\section{d) Quarta entrevista}

O paciente, ao ver-me, cumprimentou-me, disse que me chamou muito e que precisava falar comigo.

Perguntei como foi o final de semana. Informou que foi péssimo, que não saiu, que tinha recebido visita da família e de amigos e que estava bem para ir de alta.

Dirigimo-nos para o consultório e retomamos os assuntos propostos para serem discutidos no dia: a questão da droga e da dificuldade que sentia para se relacionar com as pessoas. O paciente aceitou.

Começou a falar da dificuldade em deixar de usar drogas devido à influência de amigos e da facilidade com que as encontra. Disse que quer voltar a trabalhar na loja da mãe, só que ela nao quer porque já aprontou muito (tirava dinheiro da loja para comprar drogas) e que estava pensando em voltar para Belo Horizonte, onde se dá bem com as tias.

Colocou as dificuldades que vinha sentindo (confusão e inquietação), citando alguns termos técnicocientíficos pelo abuso de drogas que explicam o que ele vinha sentindo. Reforçou que ia parar de usar drogas e apresenta como alternativas para parar: mudar de amigos, viajar, trabalhar, seguir uma religião.

Coloquei que ele tinha conhecimento do que a droga fazia e que ele tinha soluções para superar as 
dificuldades e o que estava faltando era determinação em querer parar mesmo e que muito só dependia dele.

Em relação à religião, cada hora diz que vai seguir uma: Católica, Protestante, Candomblé, Testemunha de Jeová, dizendo ser espírita e que gosta muito de ler os livros espíritas.

Foi reforçado que ele procurasse seguir aquela que o fizesse sentir-se melhor, mais aprovado.

Saiu para ir ao banheiro e retornou perguntando:

P - G., você seria capaz de gostar, de casar comigo?

E - Por que você está perguntando isso?

$\mathrm{P}$ - Você acha que alguém poderia gostar de mim de verdade?

E - Você é um rapaz bonito, inteligente e que está apenas passando por um período difícil (Coloca o paciente na realidade). E você gosta de você. (Volta o foco do assunto para ele).

P - Me acho um barato, antes não gostava de mim, as pessoas não me compreendiam mas agora não, tenho amigos que gostam de mim, tem muitas "gatas" atrás de mim.

E - Então passe a acreditar em você, confiar em você.

Começa a falar em sexo, dizendo que estava tendo relação em grupo e que pintava tudo. Perguntei se gostava. Respondeu que não, mas que acabava envolvido.

Coloquei que ele estava pensando muito em sexo e como ele se sentia diante disto. Ele respondeu que estava com problemas e que precisava deixar de fazer muita coisa que ele não gostava.

Saiu novamente, voltou dizendo que ia acabar ficando louco; que estava pensando muito, sem nada para fazer, preso ali dentro, sentindo-se só e abandonado.

Sugeri que ele conversasse com outras pessoas no hospital, que não ficasse pensando só nos seus problemas. Como não tinha interesse pelas atividades na sala de T.O., que não ficasse esperando que só os outros o procurassem, que seria bom ele sair atrás do que ele queria.

Encerrei a entrevista e marquei para 2 dias depois. Mais tarde, o paciente parou-me no corredor, pedindo para que arrumasse um colega para ficar no seu quarto, pois não queria ficar sozinho. Perguntei porque ele mesmo não tentava, respondeu que já havia chamado e que ninguém estava querendo. Pas- sou um paciente no corredor com o qual não tinha falado e perguntei-lhe se gostaria de ajudar o A.F. que estava se sentindo só. Os dois ficaram conversando e a decisão que tomaram foi a mudança de A.F. para a outra enfermaria com mais cinco pacientes.

Foi medicado no primeiro momento com Haldol 5mg 1 amp. + Fenergan 25mg 1 amp. EV., Soro glicosado $1000 \mathrm{ml}$ EV. Como prescrição diária: Haldol 5mg. 1 amp + Fenergan 25 mg 1 amp - IM de 8/8h

\section{CONSIDERAÇÕES FINAIS}

Estabelecer esta relação junto ao paciente, tentando seguir um processo sistematizado foi muito importante para nós enquanto profissional e pessoa, pois permitiu sentir com maior clareza o nível de envolvimento e comprometimento em que se deu cada entrevista.

Como já relatamos anteriormente, a preocupação ao dar assistência, era fazer uma interação a cada encontro, não planejando ou pré-estabelecendo objetivos para os demais encontros.

Com esta experiência, planejar a intervenção junto ao paciente, com base no processo da relação interpessoal, foi possível observar melhoras na capacidade do enfermeiro observar e intervir terapéuticamente junto ao paciente.

As dificuldades ocorrem em muitos momentos da interação, como por exemplo: o que falar, como conduzir e como explorar alguns assuntos trazidos pelo paciente limitando-nos, às vezes, a ouvir, deixando que expressasse o que queria, como estava se sentindo e qual a sua participação nessa experiências.

Foi interessante podermos observar que, querendo ajudar, interferimos inúmeras vezes, impondo o nosso ritmo durante a interação. Os assuntos que mais preocupavam o paciente acabavam voltando à tona. Entretanto, a seqüência que poderia levar a um maior aprofundamento, a um nível maior de confiança em nossa capacidade de ajudá-los profissionalmente pode ter sido prejudicada.

Fica claro, mesmo assim, que com o caminhar da experiência, das discussões em grupo, das avaliações feitas, foi possível desenvolver a crítica sobre as dificuldades sentidas durante as interações.

Percebemos, com clareza que, quando aprendemos a controlar nossa ansiedade, podemos ouvir mais o paciente e perceber que a maioria das soluções vem deles mesmos. É importante aprendermos a controlar 
nossa onipotência e estarmos tranqüilos para perceber que não precisamos ter respostas para tudo.

Entretanto, muito lemos para aprender e crescer para melhorar o desempenho junto ao paciente.
A presente experiência foi válida para quem vivenciou, para o grupo que discutiu, para quem orientou e conduziu os trabalhos e, possivelmente para o paciente que muito contribuiu para nosso crescimento profissional.

\section{REFERÊNCIAS BIBLIOGRÁFICAS}

1. BENJAMIN, A. A Entrevista de Ajuda. São Paulo: Martins Fontes, 1978, 195p.

2. MINZONI, M.A. Atitudes do profissional de enfermagem frente à pessoa que requer ajuda. Arquivos da Clinica Pinel, v. 6. n ${ }^{\circ}$, p. 242-6, 1980.

3. MUCHIELLI, R. A entrevista não-diretiva. São Paulo. Martins Fontes, 1978, 186p.

4. PEPLAU, H.E. Interpersonal relations in nursing. New York C.P. Putnan's, 1952. 330p.

5. RODRIGUES, A.R.F. Enfermagem de saúde mental para mulheres em crise acidental. Tese (Doutoramento) Escola de Enfermagem da Universidade de São Paulo e Escola de Enfermagem de Ribeirão Preto - USP. Ribeirão Preto, 1986
Modelos de assistência ao doente mental. $44^{\prime \prime}$ Reunião Anual da SBPC. São Paulo, 12-17/julho/92. (Programa).

Dos maneras de ayuda tetrapeutica en enfermeria psiquiátrica. Notas de Enfermeria. (no prelo).

8. ROGERS, CR. - Tornar-se Pessoa. São Paulo: Martins Fontes, 1982, 360p

9. STEFANELLI, M.C. Ensino de técnicas de comunicação terapêutica enfermeira-paciente- referencial teórico (Parte II). Rev. Esc. Enf. da USP v.21, n², p. 107-15, 1987.

Comunicação enfermeira-paciente: Teoria, ensino e pesquisa. Tese (Livre Docência). Escola de Enfermagem da Universidade de São Paulo. São Paulo, 1990, 139p.

11. TRAVELBEE, J. Intervención en Enfermeria Psiquiátrica. Colômbia: Carvajal S.A., 1982, 282p. 